\title{
Defendant physical disability and sentencing in criminal cases
}

\begin{abstract}
Two experiments were conducted to examine the impact of a defendant's physical disability on sentencing recommendations in criminal cases. In both experiments, participants were assigned to one of four conditions in a 2 (defendant gender: female, male) x2 (defendant disability: wheelchair visible or not) factorial design. Participants in both conditions also completed the Belief in Just World Scale (BJW), the Revised Legal Attitudes Questionnaire (RLAQ), and the Attitudes towards the Criminal Legal System Scale (ATCLS). Participants were then asked to recommend a sentence for the defendant ranging from no period of incarceration to life in prison and to indicate their level of confidence in the recommended sentence. In experiment 1 the defendant was convicted of murder, and in experiment 2 the defendant was convicted of embezzlement. In both experiments, longer sentences were associated with higher scores on the BJW, RLAQ, ATCLS, and male gender. No significant differences were found in recommended sentences for disabled or non-disabled offenders in either condition. Findings suggest that physically disabled offenders are treated no differently than non-physically disabled offenders regardless of defendant gender or type of crime.
\end{abstract}

Keywords: physical disability, criminal sentence, legal attitudes, belief in a just world, legal authoritarianism
Volume I Issue 4 - 2015

Richard P Conti, Deanna J Daley
Department of Psychology, Kean University, USA

Correspondence: Richard P Conti, Department of Psychology, Kean University, 1000 Morris Avenue, Union, NJ 07083, USA, Tel (908) 737-5870, Email rconti@kean.edu

Received: October 26, 2015 | Published: November 16, 2015
Abbreviations: BJW, Belief in Just World Scale; RLAQ, Revised Legal Attitudes Questionnaire; ATCLS, Attitudes towards the Criminal Legal System Scale; IRB, Institutional Review Board

\section{Introduction}

Research has consistently produced evidence of negative attitudes toward persons with both physical and psychiatric disabilities. ${ }^{1-5}$ In general, attitudes toward persons with physical disabilities are more positive than attitudes toward persons with psychiatric disabilities. ${ }^{6-8}$ Forensic research tends to focus on individuals with psychiatric disabilities as perpetrators of crime $^{9-10}$ and those with physical disabilities as victims of crime. ${ }^{11-13}$ Gradually becoming noticed is the notion of fear of crime and of groups who show fear of victimization. One group that has been rarely studied comprises individuals who have physical disabilities. Research has suggested that having a physical disability is a significant predictor of reporting fear of crime $\mathrm{c}^{13}$ and crimes against individuals with disabilities are underreported and under enforced. ${ }^{11-12}$ However, individuals with disabilities are overrepresented in the criminal justice system. ${ }^{14-17}$ Stereotypical media exposure of individuals with physical disabilities has been frequently cited, because predisposed portrayals of persons with disabilities can undesirably affect non-disabled receivers' attitudinal assessments. The media's representation of individuals with disabilities has been critiqued because individuals with disabilities are often shown in stereotypical, prejudiced, and negative ways, thus maintaining undesirable labels about individuals with disabilities. ${ }^{18}$ The negative view of disabled individuals has long history. According to Covey ${ }^{2}$ individuals with physical disabilities "have been historically classified into the stereotypes of being evil, subhuman, dependent, always seeking a miracle cure and others". Views of fairness are determined largely on the correspondence amongst judicial practice and the public. The Canadian community has a negative view of sentencing tendencies.

A majority of the community identify present sentencing tendencies to be not sufficiently severe and different in application. ${ }^{19}$ Canadian and United States data reveal that crimes of violence and sentences of incarceration are represented excessively. ${ }^{20}$ Roberts et al..${ }^{20}$ conducted three studies investigating the effects of mass media reporting on public opinions about sentencing. Individuals who read newspapers about sentencing that were in Canadian newspapers reported sentences as too sympathetic. Thus the media has a crucial part in the development and alteration of public opinion to crime, criminals, and the criminal justice system. ${ }^{20}$ Samples in Canada displayed that the public are reliant on the media to provide information on sentencing. It is possible that views of judicial leniency are at least in part due to media reporting about sentencing. ${ }^{20}$ Kitei et al., ${ }^{21}$ studied the significance of epidemiological research, issues with previous research, predominance of the prison population that are physically disabled, characteristics of the offenders, and the environment in which they are located. It is projected that there are about 220,000 inmates who have different types of physical disabilities. ${ }^{21}$ It is essential to attain information concerning the purpose for the offender's incarceration. When an offender has been traced within the prison system, it becomes vital to become aware of the type of living environment in which they are housed. The kind of housing is crucial because the housing of non-physically disabled offenders with disabled offenders has ended in emotional and physical abuse of the disabled offender. ${ }^{21}$ If the offender is not acknowledged within the system and their disability is not told to authorities, the offender may lack cooperation because of the genuine incapability to know what is required because of their disability. Workers within the criminal justice system understand that offenders with an intellectual or physical disability are disadvantaged 
because of an insufficient level of care provided to them by social services, and the level of consideration by prison and police officers, by the variety of sentence options accessible to the judiciary, and by the procedures of the organization. ${ }^{14}$ If it is unknown the number of offenders with physical disabilities that are incarcerated, it is difficult to design an effective and judicial method of intervention, care, and humane treatment for the disabled.

Early research ${ }^{22}$ reported that $1 \%$ of state and federal inmates had physical disabilities. Similar results of $1 \%$ for physical disabilities were found by Long and Sapp for state prison inmates. Petersilia ${ }^{15}$ found that $36.5 \%$ of jail inmates had a disability, with physical disabilities accounting for $10.4 \%$. Maruschack et al., ${ }^{23}$ reported that in the United States, inmates with physical disabilities make up $29.6 \%$ of the total number of state inmates and $26.5 \%$ of federal inmates; this translated to roughly 311,719 state inmates and 23,404 federal inmates with a speech, visual, or other physical disability. A follow up study ${ }^{24}$ found $40 \%$ of jail inmates with a physical disability, roughly $2 \%$ with an impairment in mobility. Forensic clinicians are expected to measure future risk and add to the strategy of care packages that will lessen possible future risk. A clinician's report can be necessary for the courts. Criminal courts process large numbers of disordered offenders and sentences including an obligation to participate in treatment that becomes a significant feature of court results. ${ }^{25}$ In the United States, it has been anticipated that clinicians contribute to approximately one million court cases each year. ${ }^{26} \mathrm{~A}$ substantial portion of criminal offenders have indicators of a psychiatric disorder at the time of their offences or at the start of sentencing. In sentencing, it is essential to have personal and general deterrence while also having and rehabilitation. ${ }^{27}$ In the situation of an offender affected by a mental disorder or abnormality, general deterrence is an aspect which should be valued less because such an offender is not a suitable example for others. ${ }^{27}$ Intellectual and physical disabilities can also be presented as mitigating factors in legal proceedings. ${ }^{28-31}$ Von Hirsch et al., ${ }^{32}$ introduce the principle of equal impact, described as "when an offender suffers from certain handicaps that would make his punishment significantly more onerous, the sanction should be adjusted in order to avoid its having an undue differential impact on him." As such, many judges will factor in an individual's disability during the sentencing process, cognizant of the fact that being disabled in prison produces undue hardships. ${ }^{32-33}$ Dullum $^{30}$ analyzed 76 sentences in Norway imposed on defendants with physical and intellectual disabilities. It was found that in most cases the court considered the disability a mitigating circumstance resulting in a reduced sentence.

The Court's reasoning for the reduction was consistent with other research ${ }^{31-33}$ stating that compared to other inmates, those with disabilities would face greater hardships in prison. Cockram ${ }^{34}$ examined judicial outcomes for people with an intellectual disability compared to other offenders. The results display that at the sentencing phase of the court procedure individuals with intellectual disabilities are treated differently than others. Cockram ${ }^{34}$ emphasizes on recognizing any variance in treatment of individuals with disabilities and finding where the difference is. The study found that $6 \%$ of charges of Sexual Assault were withdrawn for individuals with an intellectual disability, or the individual was found to be not guilty, whereas the non-disabled individuals had none of these charges withdrawn. Research involving sentencing by juries has examined the perceived attractiveness of individuals and in general, the "what is beautiful is good" stereotype ${ }^{35}$ exists. That is, attractive defendants receive less guilty verdicts and more lenient punishments. ${ }^{36-38}$ For example, Smith et al., ${ }^{39}$ conducted a study that included mock juries of three female college students each that were each asked to sentence defendants from 1 to 10years in jail. It was hypothesized that the young, good-looking defendant would be sentenced less severely than older defendants and that this effect would be more obvious in a crime of burglary than a crime of swindle, as the attractiveness of the individual may be seen as an imperative factor of the crime of swindle. It was found that attractive defendants were judged less harshly for the crime of burglary but not for the crime of swindle. Sentencing verdicts made by university students in a judicial decision-making experiment were studied by Mcfatter. ${ }^{40}$. The university students were requested to follow one of three punishment approaches (retribution, rehabilitation, or deterrence). Also, the kind of crime and the physical attractiveness of the offender were varied. It was expected that the physical attractiveness of the defendant may have had added effect on individuals following a rehabilitation approach than it would on other individuals. Butler ${ }^{28}$ found that jurors who were scored high in measures of legal authoritarian attitudes, supported and had positive attitudes toward capital punishment, were more likely to recommend a sentence of death to elderly and physically disabled offenders.

Psycholegal research involving sentencing by juries has examined several variables relating to individuals with psychiatric and intellectual disabilities; ${ }^{41}$ however, there is virtually no research involving the presence of physical disabilities on jury outcomes. The study of sentencing for criminal convictions has long been under review for the overall effectiveness, deterrence, and overall implementation of fair justice. Little empirical research has been conducted on sentencing ${ }^{42}$ since nearly $97 \%$ of federal cases and 94\% of state cases in the United States that concern criminal actions result in a plea bargain. ${ }^{43}$ Individuals with intellectual disabilities cannot take accountability for their doings. A reason for recognizing those with intellectual disabilities coming into the criminal justice system, either as perpetrators or victims of crime, is to measure the dependability and legitimacy of their actions. ${ }^{44}$ Some offenders have disadvantages because of their disability and how they are treated by criminal justice system workers. ${ }^{14}$ There is overall agreement that the level of services available to provide offenders with an intellectual disability was inadequate. ${ }^{14}$ It is imperative to recognize the core of public view concerning sentencing. Judges habitually recognize the significance of staying aware about public opinion as an influence in sentencing, there is no official approach by which the views of the public can be brought to the attention of the courts. ${ }^{19}$ If individuals with disabilities are being sentenced in a different way from the nondisabled, this will simply show differential treatment occurring at each phase of the justice process. ${ }^{34}$ If the amount of offenders with physical disabilities in prison in unknown, it is practically impossible to propose an operational and judicial system of intervention, care, and humane treatment for individuals with disabilities. Statistical analysis of sentencing procedure of the courts is questionable since punishment is often personalized. When at the sentencing phase of the court procedure, individuals with an intellectual disability seem to be treated differently. It is imperative that an appropriate range of noncustodial options be made which would let the judiciary make findings of innocence or guilt, and if guilty, to be able to offer an appropriate sentencing. ${ }^{34}$ Topics for additional research should include the reasons for the type of sentence given to those with a physical disability, to figure out the ideal way by which public view can be incorporated into sentencing procedures, and understanding the connection between physical disability and criminal behavior. 


\section{The present research}

Two studies were conducted to determine how mock jurors' attitudes toward defendants with physical disabilities related to their sentencing recommendations. In these studies, college students $(\mathrm{N}=197)$ serving as mock jurors read a simulated criminal trial in which the type of crime, the gender of the defendant, and the presence of a physical disability were varied.

\section{Experiment I:The crime of murder}

Experiment 1 examined the relationship between mock jurors' attitudes and their recommended sentence for the crime of murder. It was hypothesized that mock jurors would recommend a lesser sentence for both male and female defendants with a physical disability and for female defendants regardless of disability.

\section{Materials and methods}

\section{Participants}

Participants were undergraduate students from a Public University in the Northeastern United States. The sample consisted of 74 women and 20 men $(n=94)$ with a mean age of 23.1. The uneven gender distribution reflected the reality that more women were registered in the courses sampled (Table 1). All participants were treated in accordance with the Ethical Principles of Psychologists and Code of Conduct ${ }^{45}$ and the study was approved by the University Institutional Review Board (IRB).

Table I Participant demographics.

\begin{tabular}{|c|c|c|}
\hline & Experiment I $(n=94)$ & Experiment $2(n=103)$ \\
\hline Gender & n (\%) & n (\%) \\
\hline Female & 74 (78.7) & $77(74.8)$ \\
\hline Male & $20(2 I .3)$ & $26(25.2)$ \\
\hline \multicolumn{3}{|l|}{ Age } \\
\hline Range & $19-46$ & $19-33$ \\
\hline $19-24$ & $78(83.0)$ & $71(68.9)$ \\
\hline $25-34$ & $12(12.7)$ & $31(30.1)$ \\
\hline $35-46$ & $4(4.4)$ & I (I.0) \\
\hline Mean (SD) & $23.1(4.87)$ & $23.52(3.2)$ \\
\hline \multicolumn{3}{|l|}{ Ethnicity } \\
\hline White & $42(44.7)$ & $62(60.2)$ \\
\hline Hispanic & $27(28.7)$ & $20(19.4)$ \\
\hline Black & $20(21.3)$ & $13(12.6)$ \\
\hline Asian & $4(4.3)$ & $5(4.9)$ \\
\hline Other & I (I.I) & $3(2.9)$ \\
\hline \multicolumn{3}{|c|}{ Class standing } \\
\hline Fourth year & $51(54.3)$ & $46(44.7)$ \\
\hline Third year & 30 (31.9) & $40(38.8)$ \\
\hline Second year & II (II.7) & $5(4.9)$ \\
\hline Graduate & $2(2.1)$ & $12(11.7)$ \\
\hline
\end{tabular}

\section{Procedure}

Participants were given a packet containing an informed consent form, a demographic survey, and the following measures: Belief in a Just World Scale (BJW) ${ }^{46}$ the Revised Legal Attitudes Questionnaire (RLAQ) ${ }^{47}$ and the Attitudes toward the Criminal Legal System Scale (ATCLS) [48]. After completing the packet, each participant, through random assignment, received one of four versions of a criminal murder trial summary. A 2 × 2 between-groups factorial design was utilized to examine the effects of defendant gender (female or male), and disability (wheelchair visible or not) on mock jurors' decisions. After reading the trial summary, participants completed an additional form asking questions regarding sentencing recommendations, and how confident they were in their sentencing decision.

\section{Measures}

ATCLS: ${ }^{48}$ The ATCLS is a 24 -item scale that indicates attitudes about the criminal legal system. Items on the ATCLS are rated on a 5-point Likert-type scale ranging from 1 (Disagree Strongly) to 5 (Agree Strongly). A high score is a positive attitude toward the legal system. Cronbach's alpha is reported to be 0.82 for the ATCLS. ${ }^{48}$

BJW: ${ }^{46}$ The BJW is a 20 -item inventory designed to assess a person's belief in a just world. Individuals professing just world beliefs rationalize that people deserve what happens to them because the world is a fundamentally just and equitable place. Each item on the BJW is rated on a Likert-type scale ranging from 0 (Strongly Disagree) to 5 (Strongly Agree) with higher scores signaling stronger just world beliefs. Previous research has found that the BJW scale has acceptable levels of validity and reliability. ${ }^{49-51}$

RLAQ: ${ }^{47}$ The RLAQ consists of 23 items measured on a 6-point Likert-type scale ranging from 1 (strongly disagree) to 6 (strongly agree). The RLAQ measures levels of legal authoritarianism and demonstrates acceptable levels of validity and reliability. ${ }^{47}$ Demographic survey. Participants completed a demographic survey created for the purposes of this study indicating age, gender, marital status, race/ethnicity, and class standing.

Experiment 1: results and discussion: A 2 (defendant gender: female, male)x2 (defendant disability: wheelchair visible or not) between-groups factorial ANOVA was calculated. The means and standard deviations are presented in Table 2. The main effect for defendant gender was not significant, $\mathrm{F}(1,90)=0.308, \mathrm{p}=0.580$. The main effect for defendant disability was also not significant, $\mathrm{F}(1,90)=0.844, \mathrm{p}=0.361$. Finally the interaction was not significant, $\mathrm{F}(1,90)=1.73, \mathrm{p}=0.192$ (Figure 1).

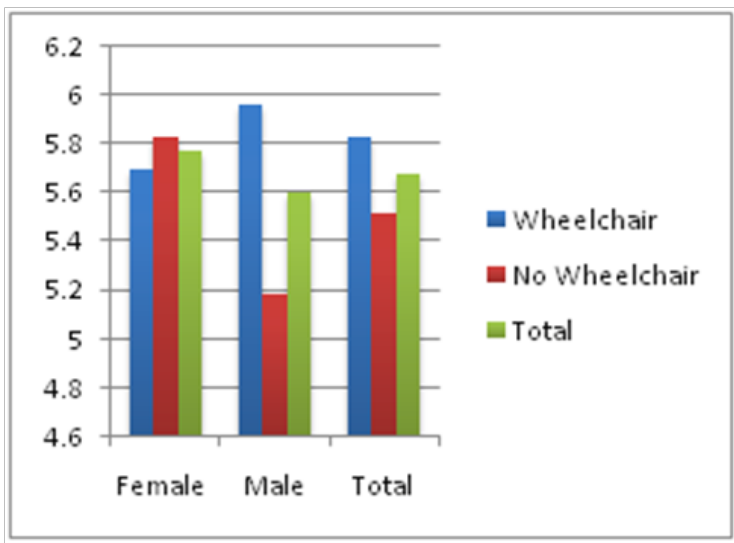

Figure I Recommended sentence for the crime of murder. 
Table 2 Means and standard deviations for each condition

\begin{tabular}{lll}
\hline & $\begin{array}{l}\text { Experiment I } \\
(\mathbf{n = 9 4})\end{array}$ & $\begin{array}{l}\text { Experiment 2 } \\
\text { (n= I 03) }\end{array}$ \\
\cline { 2 - 3 } & $\mathbf{M}(\mathrm{SD})$ & $\mathbf{M}(\mathrm{SD})$ \\
\hline Female defendant & $5.70(2.0)$ & $3.50(.9 \mathrm{I})$ \\
Wheelchair visible & $5.83(\mathrm{I} .7)$ & $3.36(\mathrm{I} . \mathrm{I})$ \\
Wheelchair not visible & $5.77(\mathrm{I} .8)$ & $3.43(\mathrm{I} .0)$ \\
Total & & \\
Male defendant & $5.96(\mathrm{I} .6)$ & $3.12(\mathrm{I} .4)$ \\
Wheelchair visible & $5.18(\mathrm{I} .4)$ & $3.48(\mathrm{I} .2)$ \\
Wheelchair not visible & & $3.3 \mathrm{I}(\mathrm{I} .3)$ \\
Total & $5.60(\mathrm{I} .5)$ & $3.32(\mathrm{I} .2)$ \\
Total & $5.83(\mathrm{I} .8)$ & $3.42(\mathrm{I} . \mathrm{I})$ \\
Wheelchair visible & $5.52(\mathrm{I} .6)$ & $3.37(\mathrm{I} . \mathrm{I})$ \\
\hline Wheelchair not visible & $5.68(\mathrm{I} .7)$ & \\
\hline
\end{tabular}

Legal authoritarianism as measured by the RLAQ was significantly related to attitudes toward the recommended sentence for the defendant $(\mathrm{r}=0.233, \mathrm{p}=0.024)$. As legal authoritarianism increased, harsher punishment was recommended. Attitudes toward the criminal legal system as measured by the ATCLS were also related toward the recommended sentence $(\mathrm{r}=0.242, \mathrm{p}=0.019)$. Positive beliefs resulted in harsher sentencing recommendations. Belief in a just world was unrelated to sentencing recommendations $(\mathrm{r}=0.059$, $\mathrm{p}=0.573$ ). Finally, participant confidence was related to sentencing recommendations $(\mathrm{r}=0.270, \mathrm{p}=0.008)$ (Figure 2). The higher levels of confidence participants reported in their recommended sentence, the harsher the sentence. Overall, contrary to expectations, the results of Experiment 1 found that disabled defendants did not receive more lenient sentences for the crime of murder than non-disabled defendants. In fact, the physically disabled male defendant received a longer sentence compared to the non-disabled defendant

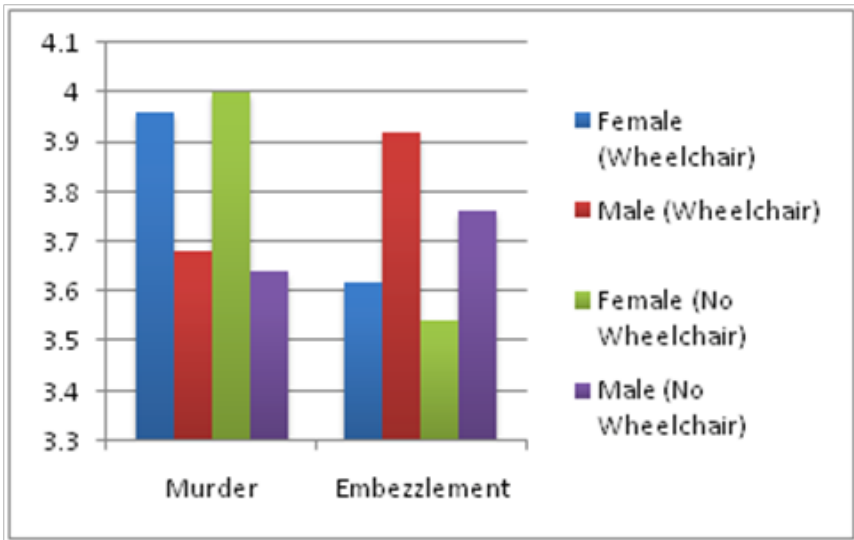

Figure 2 Participant confidence in recommended sentence.

\section{Experiment 2:The crime of embezzlement}

Experiment 2 examined the relationship between mock jurors' attitudes and their recommended sentence for the crime of embezzlement. As in Experiment 1, it was hypothesized that mock jurors would recommend a lesser sentence for both male and female defendants with a physical disability and for female defendants regardless of disability.

\section{Participants}

Participants in Experiment 2 were also undergraduate students from a Public University in the Northeastern United States. The sample consisted of 77 women and 26 men $(n=103)$ with a mean age of 23.5. As in Experiment 1, the uneven gender distribution reflected the reality that more women were registered in the courses sampled (Table 1). All participants were treated in accordance with the Ethical Principles of Psychologists and Code of Conduct ${ }^{45}$ and the study was approved by the University Institutional Review Board (IRB).

\section{Procedure}

As in Experiment 1, participants were given a packet containing an informed consent form, a demographic survey, and the BJW; RLAQ; and the ATCLS. After completing the packet, each participant, through random assignment, received one of four versions of a criminal embezzlement trial summary. A $2 \times 2$ between-groups factorial design was utilized to examine the effects of defendant gender (female or male), and disability (wheelchair visible or not) on mock jurors' decisions. After reading the trial summary, participants completed an additional form asking questions regarding sentencing recommendations, and how confident they were in their sentencing decision.

\section{Experiment 2: results and discussion}

A 2 (defendant gender: female, male) x 2 (defendant disability: wheelchair visible or not) between-groups factorial ANOVA was calculated. The means and standard deviations are presented in Table 2. The main effect for defendant gender was not significant, $F(1,99)=0.311, p=0.578$. The main effect for defendant disability was also not significant, $F(1,99)=0.220, p=0.640$. Finally the interaction was not significant, $\mathrm{F}(1,99)=1.21, \mathrm{p}=0.273$ (Figure 3).

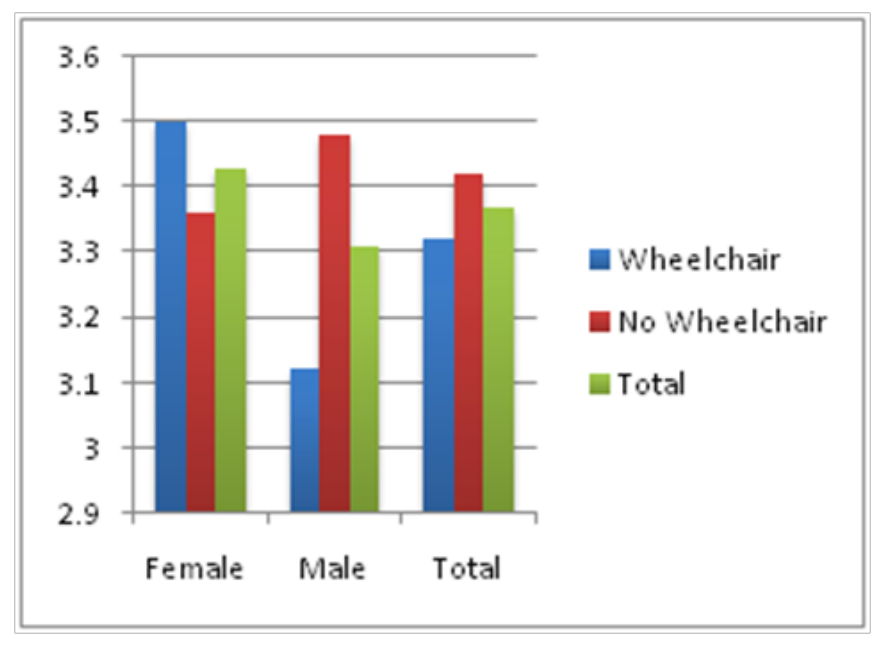

Figure 3 Recommended sentence for the crime of embezzlement.

Legal authoritarianism as measured by the RLAQ was unrelated to attitudes toward the recommended sentence for the defendant $(\mathrm{r}=0.044, \mathrm{p}=0.662)$. Attitudes toward the criminal legal system were related toward the recommended sentence $(\mathrm{r}=0.238, \mathrm{p}=0.015)$. Positive beliefs resulted in harsher sentencing recommendations. 
Belief in a just world was unrelated to sentencing recommendations $(\mathrm{r}=-0.013, \mathrm{p}=0.899)$. Finally, participant confidence was unrelated to sentencing recommendations $(\mathrm{r}=0.128, \mathrm{p}=0.196)$ (Figure 2). Similar to the findings in Experiment 1, the results of Experiment 2 found that disabled defendants did not receive more lenient sentences for the crime of embezzlement

\section{Conclusion}

Despite the fact that a physical disability can be presented as a mitigating factor in legal proceeding ${ }^{28-31}$ and previous research suggesting that defendants with physical disabilities receive reduced sentences,${ }^{30}$ the findings of the present study indicate that defendants with physical disabilities were treated no differently than defendants without disabilities. Although previous jury simulation research has suggested few differences between student samples and nonstudent samples in decision-making, ${ }^{52,53}$ college students in the present study may be unfamiliar with the intricacies involved in the actual sentencing process, including the hardships faced in prisons by individuals with physical disabilities. It should also be taken into consideration that college students have more interaction with individuals with disabilities, and many college courses include information on individuals with disabilities. Research has shown that such courses are effective in changing attitudes toward disabilities. ${ }^{54}$ Another factor to consider in the present study is that participants read a scenario in one of two conditions while viewing a photograph of the defendant in each condition. There was no deliberation among participants as would exist in an actual trial. A major criticism of jury simulation studies is the use of non-deliberating jurors. ${ }^{53,55}$ Deliberating jurors reason at a higher level regarding materials and evidence about the case and tend to be less influenced by factors such as inadmissible evidence..$^{55}$ The results of the present study could be interpreted in a positive light. That is, the fact that defendants with physical disabilities were treated no differently than those without disabilities is a testament to the fact that attitudes toward individuals with disabilities are changing in a positive direction. Future research on this topic should include non-student populations and deliberation among participants in decision-making. If such studies yield findings similar to the present study, it would provide further evidence that societal attitudes toward individuals with disabilities are indeed changing.

\section{Acknowledgments}

None.

\section{Conflicts of interest}

The author declares that there are no conflicts of interest.

\section{References}

1. Antonak RF, Livneh H. Measurement of attitudes towards persons with disabilities. Disabil Rehabil. 2000;22(5):211-224.

2. Covey HC. Social perceptions of people with disabilities in history. In: Charles C Thomas, editor. Springfield, USA. 1998;305 p.

3. Pruett S, Lee E, Chan F, et al. Dimensionality of the Contact With Disabled Persons Scale: Results from exploratory and confirmatory factor analyses. Rehabil Couns Bull. 2008;51(4):210-220.

4. Vilchinsky N, Findler L, Werner S. Attitudes toward people with disabilities: The perspective of attachment theory. Rehabil Psychol. 2010;55(3):298-306.

5. Wright BA. Physical disability: A psychosocial approach. (2nd ed) HarperCollins Publishers, New York, USA. 1983;544 p.
6. Cook D. Psychosocial impact of disability. In: Parker RM, editor. Rehabilitation counseling: Basics and beyond. (3rd ed), Austin. 1998;303-326.

7. Livneh H. On the origins of negative attitudes towards people with disabilities. Rehabil Lit. 1982;43(11-12):338-347.

8. Wong DW, Chan F, Cardoso E, et al. Rehabilitation counseling students' attitudes toward people with disabilities in three social contexts: A conjoint analysis. Rehabil Couns Bull. 2004;47(4):194-204.

9. Abramsky S, Fellner J. Ill-equipped:U.S. prisons and offenders with mental illness. Human Rights Watch, New York, USA. 2003;223 p.

10. Torrey EF, Kennard AD, Eslinger D, et al. More mentally ill persons are in jails and prisons than hospitals: A survey of the states. Treatment Advocacy Center, Arlington, USA. 2010;22 p.

11. Harrell E, Rand M. Crimes against people with disabilities, 2008. Bureau of Justice Statistics, USA. 2010;16 p.

12. Sherry M. Disability Hate crimes: Does anyone really hate disabled people? Burlington, USA. 2010.

13. Stiles LB, Halim S, Kaplan BH. Fear of crime among individuals with physical limitations. Crim Just Rev. 2003;28(2):232-253.

14. Cockram J, Jackson R, Underwood R. People with an intellectual disability and the criminal justice system: The family perspective. $J$ Intellect Dev Disabil. 1998;23(1):41-56.

15. Petersilia J. Doing justice? Criminal offenders with developmental disabilities. Detailed Research Findings. California Research Center, University of California, USA. 2000;60 p.

16. Smith T, Polloway EA, Patton JR, et al. Individuals with intellectual and developmental disabilities in the criminal justice system and implications for transition planning. Educ Train Dev Disabil. 2008;43(4):421-430.

17. Zhang D, Hsu HY, Katsiyannis A, et al. Adolescents with disabilities in the juvenile justice system: Patterns of recidivism. Except Child. 2011;77(3):283-209.

18. Von Sikorski C, Schierl T. Attitudes in context: Media effects of salient contextual information on recipients' attitudes toward persons with disabilities. J Media Psychol. 2014;26(2):70-80.

19. Gebotys R, Roberts J. Public views of sentencing: The role of offender characteristics. Can J Behav Sci. 1987;19(4):479-488.

20. Roberts J, Doob A. News media influences on public views of sentencing. Law Hum Behav. 1990;14(5):451-468.

21. Kitei N, Sales B. Epidemiology of physically disabled offenders. J Dev Phys Disabil. 2008;20(4):399-413.

22. Veneziano L, Veneziano C. Disabled inmates. In: McShane M \& Williams F (Eds.). Encyclopedia of American prisons New York, USA. 1996; 157-161.

23. Marushack LM, Beck AJ. Medical problems of inmates, 1997. Bureau of Justice Statistics: Special Report. Office of Justice programs, Washington, USA. 2001;12 p.

24. Maruschack LM. Medical problems of jail inmates. Bureau of Justice Statistics: Special Report. Office of Justice programs, Washington, USA. 2006;9 p.

25. Ross S, Lawrence J. Sentencing mentally disordered offenders: Factors that predict sentencers' decisions about treatment. Psychiatr Psychol Law. 2005;12(1):174-183.

26. Faust D, Ziskin J. The expert witness in psychology and psychiatry. Science. 1988;241(4861):31-35.

27. Freckelton I. Sentencing Offenders with Impaired Mental Functioning R v Verdins, Buckley and Vo [2007] VSCA 102; (2007) 169 A Crim R 581 Maxwell P, Vincent and Buchanan JJ. Psychiatr Psychol Law. 2007; 14(2):359-363. 
28. Butler B. Moving beyond Ford, Atkins, and Roper: Jurors' attitudes toward the execution of the elderly and the physically disabled. Psychol Crime Law. 2010;16(8):631-647.

29. Demleitner N, Berman D, Miller ML, et al. Sentencing law and policy: Cases statutes and guidelines. 3rd ed. Aspen publishers., New York, USA. 2013.

30. Dullum J. Sentencing offenders with disabilities. Scand J Disabil Res. 2015;1-14.

31. Timmons KC. Disability-related misconduct and the legal profession: The role of the Americans with Disabilities Act. $U$ Pitt $L$ Rev. 2008;69:609-635.

32. Von Hirsch A, Ashworth A. Proportionate sentencing: Exploring the principles. Oxford University Press, New York, USA. 2005;46(5):955-959.

33. Johnston EL. Conditions of confinement at sentencing: The case of seriously disordered offenders. Cath UL Rev. 2014;63:625-678.

34. Cockram J. Justice or differential treatment? Sentencing of offenders with an intellectual disability. J Intellect Dev Disabil. 2005;30(1):3-13.

35. Dion K, Berscheid E, Walster E. What is beautiful is good. J Pers Soc Psychol. 1972;24(3):285-290.

36. Efran MG. The effect of physical appearance on the judgment of guilt, interpersonal attraction, and severity of recommended punishment in a simulated jury task. J Res Pers. 1974;8(1):45-54.

37. Mazzella R, Feingold A. The effects of physical attractiveness, race, socioeconomic status, and gender of defendants and victims on judgments of mock jurors: A meta-analysis. J Appl Soc Psychol. 1994;24(15):1315-1338.

38. Wuensch KL, Chia RC, Castellow WA, et al. Effects of physical attractiveness, sex, and type of crime on mock juror decisions: Areplication with Chinese students. J Cross Cult Psychol. 1993;24(4):414-427.

39. Smith E, Hed A. Effects of offenders' age and attractiveness on sentencing by mock juries. Psychol Rep. 1979;44(3):601-694.

40. McFatter R. Sentencing strategies and justice: Effects of punishment philosophy on sentencing decisions. $J$ Pers Soc Psychol. 1978;36(12):1490-1500.
41. Vidmar N, Hans VP. American juries: The verdict. Law \& Society Review. 2007;43(4):958-960.

42. Brewer N, Williams KD. Psychology and law: An empirical perspective. Guilford Press, New York, USA. 2005;17(3):191-192.

43. Missouri v Frye, 132 S. Ct. 1399. The Mayhem-Hite Report. 2012.

44. Jahoda A. Offenders with a learning disability: The evidence for better services? J Appl Res Intellect Disabil. 2002;15(2):175-178.

45. Ethical Principles of Psychologists and Code of Conduct. American Psychological Association. Washington, USA. 2002.

46. Rubin Z, Peplau LA. Who believes in a just world? J Soc Issues. 1975;31(3):65-90.

47. Kravitz DA, Cutler BL, Brock P. Reliability and validity of the original and revised Legal Attitudes Questionnaire. Law Hum Behav. 1993;17(6):661-677.

48. Martin TA, Cohn ES. Attitudes toward the criminal legal system: Scale development and predictors. Psychol Crime Law. 2004;10(4):367-391.

49. Furnam A. Belief in a just world: Research progress over the past decade. Pers Individ Dif. 2003;34(5):795-817.

50. Furnham A, Proctor E. Belief in the just world: review and critique of the individual differences literature. Br J Soc Psy. 1989;28(4):365-384.

51. Hellman CM, Muilenburg-Trevino EM, Worley JA. The belief in a just world: An examination of reliability estimates across three measures. $J$ Pers Assess. 2008;90(4):399-401.

52. Bornstein BH. The ecological validity of jury simulations: Is the jury still out? Law Hum Behav. 1999;23(1):75-91.

53. Diamond SS. Illuminations and shadows from jury simulations. Law Hum Behav. 1997;21(5):561-571.

54. Campbell J, Gilmore L, Caskelly M. Changing student teachers' attitudes towards disability and inclusion. J Intellect Dev Disabil. 2003;28(4):369-379.

55. Nuñez N, McCrea SM, Culhane SE. Jury decision making research: Are researchers focusing on the mouse and not the elephant in the room? Behav Sci Law. 2011;29(3):439-451. 